\title{
Impact of the substitution distribution and the interlayer distance on both the surface energy and the hydration energy for Pb-montmorillonite
}

\author{
Fabrice Salles ${ }^{\mathrm{a}, *}$, Jean-Marc Douillard ${ }^{\mathrm{b}}$, Olivier Bildstein ${ }^{\mathrm{c}}$, Henri Van Damme ${ }^{\mathrm{d}}$ \\ a Institut Charles Gerhardt Montpellier Equipe PMDP, UMR CNRS 5253, UM2, ENSCM-Université Montpellier II, Place E. Bataillon, 34095 Montpellier Cedex 05, France \\ Institut Charles Gerhardt Montpellier Equipe AIME, UMR CNRS 5253, UM2, ENSCM-Université Montpellier II, Place E. Bataillon, 34095 Montpellier Cedex 05, France \\ CEA, DEN, SMTM/Laboratoire de Modélisation des Transferts dans l'Environnement, Cadarache, F-13108 Saint Paul Les Durance, France \\ ESPCI-Paris Tech, UMR 7615, CNRS-UPMC-ESPCI, 10 rue Vauquelin, 75231 Paris Cedex 05, France
}

A R T I C L E I N F O

Article history:

Received 29 October 2009

Received in revised form 29 August 2010

Accepted 2 September 2010

Available online 9 September 2010

\section{Keywords:}

Electrostatic calculations

Lead

Montmorillonite

Surface energy

Hydration energy

Layer charge

\begin{abstract}
A B S T R A C T
The understanding of the adsorption of charged species in swelling clays is of primary importance to optimise the capture of heavy metal ions in soils. Adsorption is expected to depend on the microscopic structure of the clay, which varies strongly with the origin and history (hydration-desorption cycles, temperature ....) of the sample. Then it is necessary to evaluate the distinct interaction energies between water molecules, interlayer cations and clay surfaces, taking into account the position of the substitutions in the clay layer. Here we propose an investigation of plausible structures of some $\mathrm{Pb}$-montmorillonites differing by their interlayer distances, their layer charges and the distribution of substitutions in octahedral sheet from a modelling approach, looking at the evolution of the partial charges in these structures. Using a methodology previously developed in the simpler case of alkali cations, we also estimate the surface energy in the dry state and then the details of the hydration energy for the cation and for the clay layer to interpret the capacity of ion adsorption in swelling clays to capture heavy metals. We conclude from our calculations that a cell structure with intermediate layer charge (close to 0.5 per unit cell) is probably the best candidate to allow the capture of the $\mathrm{Pb}^{2+}$ as interlayer cations considering the electrostatic effect. The hydration process of the cation appears as the most energetic part of the hydration of swelling clays compared to the interactions with the layer, but the cation mobility is limited since the hydration process is not complete. This means that the heavy metal ions, present in the interlayer space, will be unable to diffuse and will be captured in the case of a low layer charge.
\end{abstract}

D 2010 Elsevier B.V. All rights reserved.

\section{Introduction}

Scientific progress has improved human life in various domains Serrano et al., 2005; Chaturvedi et al., 2006; Yot and Méar, 2009). However, natural systems have been strongly modified, which affects both health and environment (Sen Gupta and Bhattacharyya, 2008; Babel and Kurniawan, 2003). In particular, the presence of metallic ions in the environment is responsible for the contamination of living organisms (Chaturvedi et al., 2006). This is why the reduction of the quantity of metal present in water or in soil represents a big challenge in order to avoid harmful effects to humans (Volzone, 2004). Moreover, the understanding of both their diffusion and adsorption properties is essential in order to foresee the risks for the ecosystem (Chaturvedi et al., 2006). Heavy metals are the high-density metallic elements of the periodic classification. Some metals are extremely harmful (mercury, lead, cadmium, and chromium (VI)). It is therefore necessary to propose adequate procedures in order to avoid (i)

* Corresponding author. Tel.: + 334671433 07; fax: + 33467144290 .

E-mail address: fsalles@ipmc.univ-montp2.fr (F. Salles). possible bio-accumulation and redissolution of metals in the ecosystem and (ii) reaching the critical metal concentration that is dangerous for some living organisms.

The research for the purification of water contaminated with heavy metals has led to the development of new processes, such as coprecipitation, coagulation and extraction in solvents in the case of liquid or ionic mercury (Lima and Araujo, 1994; Blanchard et al. 1984). The immobilisation of metals by precipitation or sorption is considered as the most efficient way to reduce the quantity of metal in contaminated soils (Vega et al., 2009; Pavlovic et al., 2009; Bhattacharyya and Sen Gupta, 2008; Sen Gupta and Bhattacharyya, 2008; Sipos et al., 2008; Singh et al., 2001). Different solids, such as zeolites, activated carbons, silicas (specially the natural, modified or pillared clays) are potential candidates for metal retention (Lantenois et al., 2007; Singh et al., 2001; Matthes et al., 1999; Pinnavaia et al. 1985). In waste storage sites, compacted natural clays are present in great quantity and their properties for cationic exchange capacity or hydraulic conductivity make them efficient adsorbents. The adsorption capacity for metallic cations has already been studied and the following order has been found: $\mathrm{Cr}>\mathrm{Ni}>\mathrm{Zn}>\mathrm{Cu}>\mathrm{Co}>\mathrm{Pb}$ for a $\mathrm{Na}-$ montmorillonite (Abollino et al., 2003). Due to their large specific 
surface areas and high cation exchange capacity, the swelling clays display a strong capacity to capture metallic cations. To elucidate the role of the clay framework and predict the capacity of adsorption for ions, the molecular approach is a powerful tool. Moreover molecular simulation can allow determination of the important structural parameters that have to be considered to improve the adsorption capacity for ions. In addition, the hydration state of the sample strongly influences the mobility and the interaction of the cation in the interlayer space. The understanding of the hydration process in these solids is therefore a crucial step to completely elucidate the mechanism of heavy metal capture in swelling clays.

This paper focuses on the determination of the surface energy in the dry state which is linked to the cohesion energy between clay layers. This energy has to be counterbalanced during the clay hydration (Salles et al., 2006; Douillard et al., 2007a,b). It follows that the knowledge of the surface energy is the initial step to estimate the hydration capacity of a solid. The calculation of the hydration energy for the interlayer cation and the surface layer completes the description of the hydration and allows the elucidation of the driving force for the hydration in swelling clays (Salles et al., 2007). Such a method has been successfully compared with a recent interpretation of the conductivity measurements (Salles et al., 2008) and calorimetry data (Salles et al., 2009). For this complete description, we have to build a consistent structure for ideal montmorillonites saturated with $\mathrm{Pb}^{2+}$ cations. Then we propose to study the influence of both the layer charge and the opening of the interlayer space using electrostatic calculations. Since no structural data is available today for montmorillonite saturated with the $\mathrm{Pb}^{2+}$ cation at the dry state, we have to propose, as a first step, a "plausible" structure, before having a microscopic view of the adsorption of heavy metal ions. This is why the influence of the layer charge by imposing different substitution positions in different surface charge structures is studied. The impact of these substitutions on the surface energy and the chemical reactivity are also discussed.

\section{Computational section}

\subsection{Theoretical approach}

\subsubsection{Lattice energy}

The first step of the calculation is the classical computation of the lattice energy in a crystal using the Madelung matrix, corresponding to the summation of the electrostatic influence relative to the different positions of the atoms constituting the crystal. For this, the crystal structure, including $\mathrm{H}$ atoms, the relationships defined by the space group of the crystal and the formal charges have to be known. Details of such calculations giving the Madelung constant $\mathrm{M}$ and the Madelung tensor Mij are given elsewhere (Quane, 1970). One result obtained from our calculations is the value of the electrostatic part for the lattice energy, i.e. the actual attractive part of this energy, when considering ionic solids (Douillard and Henry, 2003; Huheey et al., 1993).

$U_{e}=-\frac{N_{\mathrm{a}} M e^{2}}{r_{\mathrm{e}}}$

where $U_{e}, N_{a}, M$, e and $r_{e}$ correspond to the lattice energy, the Avogadro number, the Madelung constant, the electron charge and the internuclear distance respectively. The choice of $r_{e}$ is detailed in Quane (1970). It must be emphasized that the preliminary calculation of the lattice energy considers that the crystal is fully ionic.

\subsubsection{Atomic charge}

Pauling suggested that the effective electrical charge located on a chemical species interacting in a chemical bond is related to the electronegativity of the atom, which represents its capacity to attract electrons. Another concept is necessary in order to interpret the chemical bonds quantitatively in such a way: the hardness corresponding to the measure of resistance of a chemical species to change its electronic configuration (Pauling, 1932). The formalization of electronegativity and hardness concepts has been carried out in the framework of density functional theory (Parr and Yang, 1994). In this theory the chemical potential $\mu$ of the electrons of the studied system is the derivative of the energy, $\mathrm{E}$, with respect to the number of electrons, $\mathrm{N}$, at constant external potential, $v$. It is also defined as a definition of the electronegativity $\chi$ :

$\mu=(\partial E / \partial N)_{v}=-\chi$.

The hardness $\eta$ is then

$\eta=\left(\frac{\partial^{2} E}{\partial N^{2}}\right)_{v}=\left(\frac{\partial \mu}{\partial N}\right)_{v}$

Practically, it is possible to determine the global distribution of the electron density around atoms in a molecule or a crystal using scales for electronegativity and hardness. For this, it is necessary to compute the equalization of the chemical potentials of the different atomic charge clouds upon bond formation, and then to determine atomic charges. It is very simple for diatomic molecules A-B: for any electron transfer $\mathrm{dN}$ from $\mathrm{B}$ to $\mathrm{A}$ at the internuclear distance $\mathrm{r}$, the change in energy is the following using the same notations:

$d E=\left[\left(\frac{\partial E}{\partial N_{A}}\right)_{N_{B}, r}-\left(\frac{\partial E}{\partial N_{A}}\right)_{N_{A}, \mathrm{r}}\right] d N+\left(\frac{\partial E}{\partial r}\right)_{N_{\mathrm{A}}, N_{\mathrm{E}}} d r$

In this case, the equilibrium imposes $d r=0$ (i.e. $r=r_{e}$, where $r_{e}$ is the internucleus equilibrium distance) and $\mathrm{dE}=0$. It follows that the equation is simplified into:

$0=\left[\left(\frac{\partial E}{\partial N_{A}}\right)_{N_{B}, T_{e}}-\left(\frac{\partial E}{\partial N_{\mathrm{a}}}\right)_{N_{A}, T_{\varepsilon}}\right] d N$.

There is an equalization of the effective electronegativities of $A$ and $B$ (denoted $\chi_{A}$ and $\chi_{B}$ ), ensured by the change $\mathrm{dN}$ of the effective atomic charges $\mathrm{q}_{\mathrm{i}}$. Then, using the previously mentioned definition of the hardness, one gets a relation between the atomic electronegativities $\chi_{i}^{0}$ of pure/single isolated species, the charges $\mathrm{q}_{\mathrm{i}}$, the hardnesses $\eta_{\mathrm{i}}$ and the resulting mean electronegativity $\bar{\chi}$ which corresponds to the value obtained at equilibrium:

$\chi_{\mathrm{A}}=\chi_{\mathrm{A}}^{0}+\eta_{\mathrm{A}} q_{\mathrm{A}}=\chi_{\mathrm{B}}^{0}+\eta_{\mathrm{B}} q_{\mathrm{B}}=\chi_{\mathrm{B}}=\bar{\chi}$

which gives for the charge, since $\mathrm{q}_{\mathrm{A}}=\mathrm{q}_{\mathrm{B}}: q_{\mathrm{A}}=\frac{\chi_{\mathrm{B}}^{0}-\chi_{\mathrm{A}}^{0}}{\eta_{\mathrm{A}}+\eta_{\mathrm{B}}}$

From this equation, the difference of electronegativities can be considered as driving the electron transfer, in contrast with the sum of hardnesses which is opposed to this transfer.

However, this calculation, simple in the case of diatomic molecules, becomes more complex in the case of crystals, where long-range forces act and a spatial summation is performed. It is therefore necessary to know equilibrium distances for all atoms in the crystal. We will discuss this in the next paragraph.

In the calculation, the Allen electronegativity scale, which is related to spectroscopic characteristics of the atom, is used (Huheey et al., 1993; Allen, 1989).

In addition, the model supports the hardness scale linked to the radius of the atom considered as a sphere with a uniformly distributed electric charge q (Henry, 1997). The radius is taken here as the size of the diffuse orbital of the element (this hardness scale is detailed in Henry, 1997). The calculation is then independent from the assumptions or relative scales but depends only on physical values that can be 
determined by spectroscopic techniques or quantum calculations. The other main interest of such a calculation is the fact that no value of the charge for a chosen atom has to be assumed, which is unfortunately often the case in the calculations in the literature (Rotenberg et al., 2007; Marry et al., 2002; Skipper et al., 1995). Values for the hardness are given in Table 1.

\subsubsection{Calculations for crystals and layers}

In the case of infinite crystals and using crystallographic data, the mean electronegativity is determined by the following equation:

$\bar{\chi}=\chi_{\mathrm{i}}^{0}+\frac{e}{4 \pi \varepsilon_{0} r_{\mathrm{i}}} q_{\mathrm{i}}+\frac{1}{4 \pi \varepsilon_{0}} \sum_{j=1}^{n} M_{i, j} e q_{j}$ with $\sum_{i=1}^{n} q_{i}=z$.

One has to emphasize that the Madelung tensor $\mathrm{M}_{\mathrm{i}, \mathrm{j}}$ takes into account the geometry of the studied crystal, and is computed from atom positions using routine procedures. The computation of the atomic charges $\mathrm{q}_{\mathrm{i}}$ is then straightforward. Knowing this distribution, a summation named by Henry (1997) the "Electrostatic Balance" (EB) is calculated.

$E B=\frac{e^{2}}{8 Z \pi \varepsilon_{0}} \sum_{i=1}^{n} \sum_{j=1}^{n} M_{i, j}\left(q_{i} q_{j}\right)$

By considering the ionic charges instead of the atomic charges in Eq. (8), this equation corresponds to the electrostatic part of the lattice energy, $U_{e}$, defined in Eq. (1) (the Madelung tensor gives the Madelung constant). Then, EB corresponds to the effective electrostatic part of the bond energy. It has already been shown that the electrostatic part of the energy, taking into account the repulsive forces, corresponds to $90 \%$ of the attractive part, at the first approximation (Huheey et al., 1993). The calculation in a semiinfinite solid is very expensive in computer memory and is performed only on a limited number of atoms (Bertaut, 1952). We consider that the results are close to the calculations in a semi-infinite crystal since the curve representing the energy evolution as a function of the number of atoms considered in our calculations converges (see Fig. 2).

In this general framework and using crystallographic software, models with finite layers, developed along different axes or $h k l$ planes, are built. It is assumed that only long-range forces are modified when comparing infinite crystal and finite layer. Indeed, a strong modification of the electrostatic energy is observed when developing a layer. This energy can be extrapolated to a value corresponding to a layer, infinite in two directions of space and finite in the other one. Assuming that the other parts of the energy (mainly due to dispersive forces) do not vary when, modifying the dimension of the layer, the difference of calculated electrostatic energies reported to a surface area unit can be considered as the total variation of the attractive energy between a semi-infinite layer and an infinite crystal (Douillard and Henry, 2003). Finally, it can be considered as the cohesive energy of the crystal; i.e. the energy required to separate the layers composing the crystal. For that, we divide the energy difference between the crystal and the layer by the cell surface area of the

Table 1

Hardness values used for the atoms.

\begin{tabular}{ll}
\hline Atom & Hardness $(\mathrm{nm})$ \\
\hline $\mathrm{Si}$ & 0.1068 \\
$\mathrm{O}$ & 0.045 \\
$\mathrm{Mg}$ & 0.1279 \\
$\mathrm{Al}$ & 0.1312 \\
$\mathrm{H}$ & 0.053 \\
$\mathrm{~Pb}$ & 0.1215 \\
\hline
\end{tabular}

considered layer, which can be directly determined from the crystallographic data (a, b, c, and $\gamma$ parameters).

We obtain the following equation derived in the unit cell to calculate the cohesion energy of the solid per unit surface area.

$U_{\text {coh }}^{\text {attr }}=[U($ crystal $)-U($ layer $)] \approx[E B($ crystal $)-E B($ layer $)] / A_{s}^{c}$

where $A_{\mathrm{s}}^{\mathrm{c}}$ is the surface area of the considered layer.

Such a layer is represented in Fig. 1.

If the considered layer is built along two crystal axes, proportionally to the cell dimensions, it is easy to relate the surface area acting in the defined process to the molecular lengths, linked to the cell lengths a, b and c. By definition, per unit surface area, the energy of cohesion is twice the surface energy.

In the case of clays, our calculation makes it possible to obtain the energy of cohesion between the different layers along the c-axis, which is perpendicular to the ideal plane of cleavage (Salles et al., 2007; Douillard et al., 2007b).

\subsection{Crystallographic structures}

The use of a correct crystallographic file is the starting point in our calculation. We must dispose of a structure with the precise atom positions in order to get meaningful calculations. However, due to the lack of information concerning the structure of Pb-montmorillonite, we have to start from the structure established by Tsipurski and Drits (1984). In this structure, the nature of the interlayer cations and the c parameter in the unit cell have been modified (see discussion in the later part). Selected crystallographic data are given in Table 2.

Montmorillonite is a phyllosilicate formed by aluminosilicate layers stacked one above the other and each layer is composed of silicon, aluminium, magnesium and oxygen. A simplified formula is: $(\mathrm{Na}, 0.5 \mathrm{Ca})_{0.6}(\mathrm{Al}, \mathrm{Mg})_{4} \mathrm{Si}_{8} \mathrm{O}_{20}(\mathrm{OH})_{4}, \mathrm{nH}_{2} \mathrm{O}$. The $\mathrm{Na}$ and $\mathrm{Ca}$ cations are called interlayer cations since they are placed between the aluminosilicate layers. In the considered structure, both the existence of tetrahedral substitutions and the presence of the iron atom in the layer are not taken into account, in agreement with hypotheses commonly accepted in simulation works (Rotenberg et al., 2007; Marry et al., 2002; Skipper et al., 1995).

In the clay layer, a partial substitution of aluminium atoms by magnesium atoms can occur in the octahedral sheet. Similarly silicon atoms can be replaced in the tetrahedral sheet by aluminium atoms, but, as mentioned previously, this kind of substitutions is not considered here. The existence of substitution creates a negative charge, compensated by an interlayer cation. The interlayer cations present in natural samples are $\mathrm{Na}^{+}, \mathrm{Ca}^{2+}$, and $\mathrm{Mg}^{2+}$.

The montmorillonite structure can be built in the space group $\mathrm{C} 2 / \mathrm{m}$ (\#12), but some octahedral site positions have to be empty. With the code PACHA, it is simpler to start from a C2 symmetry. For our calculations, we consider the Tsipurski and Drits structure (Tsipurski and Drits, 1984)
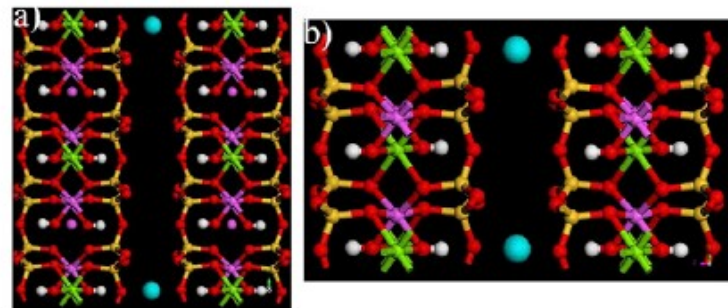

Fig. 1. Schematic representation of the $\mathrm{Pb}$-montmorillonite unit cell along the $\mathrm{b}$ and $\mathrm{c}$ axes for the low charge (a) and the high charge (b) structures. The colors correspond to the following atoms: white $(\mathrm{H})$, cyan $(\mathrm{Pb})$, purple $(\mathrm{Mg})$, green $(\mathrm{Al})$, red $(\mathrm{O})$, and yellow (Si). 
Table 2 Crystallographic data for the low charge and high charge structures of Pb-montmorillonite studied.

\begin{tabular}{lll}
\hline Crystallographic formula & $\mathrm{Pb}_{0.5} \mathrm{Si}_{8} \mathrm{Al}_{3} \mathrm{Mg}_{1} \mathrm{O}_{24} \mathrm{H}_{4}$ & $\mathrm{PbSi}_{8} \mathrm{Al}_{2} \mathrm{Mg}_{2} \mathrm{O}_{24} \mathrm{H}_{4}$ \\
Space group & $\mathrm{P} 1$ & $\mathrm{C} 2 / \mathrm{m}$ \\
$\mathrm{a}(\mathrm{nm})$ & 0.517 & 0.518 \\
$\mathrm{~b}(\mathrm{~nm})$ & 1.788 & 0.898 \\
$\mathrm{c}(\mathrm{nm})$ & 1.03 & 1.030 \\
Alpha & 90 & 90 \\
Beta & 90 & 99.54 \\
Gamma & 90 & 90 \\
$V\left(\mathrm{~nm}^{3}\right)$ & 0.95213 & 0.4725 \\
\hline
\end{tabular}

where the cell dimensions for the Na-montmorillonite are: $\mathrm{a}=0.517 \pm$ $0.002 \mathrm{~nm}, \mathrm{~b}=0.894 \pm 0.002 \mathrm{~nm}, \mathrm{c}=0.995 \pm 0.006 \mathrm{~nm}, \beta=99^{\circ} 54^{\prime} \pm 30^{\prime}$. The introduction of $\mathrm{Pb}^{2+}$ as interlayer cation surely imposes a certain modification of the $\mathrm{c}$ value, corresponding to the interlayer opening. Such a choice is delicate, since modifications of $a$ and $b$ values should also be possible (Drits and Tchoubar, 1990). We propose here to study the evolution of the electrostatic properties for two values, $\mathrm{c}=1.03 \mathrm{~nm}$ and $c=1.15 \mathrm{~nm}$. The first value corresponds to the known interlayer distance at the dry state for $\mathrm{Ca}^{2+}$-montmorillonite, and then assumes that the $\mathrm{Pb}^{2+}$ occupies the same steric volume as $\mathrm{Ca}^{2+}$ (see Ferrage et al., 2005). The second value corresponds to an extreme interlayer distance corresponding to the sum of the standard layer thickness (c $\sim 1 \mathrm{~nm})$ and a realistic ionic radius of $\mathrm{Pb}^{2+}(0.15 \mathrm{~nm})$ (Marcus, 1994). Some other intermediate values have been also investigated.

Moreover the influence of the layer charge has also been investigated. We have considered for one $\mathrm{Pb}^{2+}$ cation two different unit cells (corresponding to one and two substitutions for $\mathrm{O}_{20}(\mathrm{OH})_{4}$ ) as illustrated by the schematic representations given in Fig. 1. Compositions are modified in order to reproduce the charge effect. The respective compositions are $\mathrm{Pb}\left(\mathrm{Si}_{8} \mathrm{Al}_{2} \mathrm{Mg}_{2} \mathrm{O}_{24} \mathrm{H}_{4}\right)$ and $\mathrm{Pb}_{0.5}$ $\left(\mathrm{Si}_{8} \mathrm{Al}_{3} \mathrm{Mg}_{1} \mathrm{O}_{24} \mathrm{H}_{4}\right)$. The substitutions have been imposed in the octahedral sheet in order to stay close to the montmorillonite structure. The main difference is the $\mathrm{Mg} / \mathrm{Al}$ ratio, which is respectively 1 and $1 / 3$ for the two structures considered in this article. Therefore we consider a strong layer (or surface) charge $(+1)$ and a lower layer charge $(+0.5)$ per $\mathrm{O}_{24} \mathrm{H}_{4}$. In the following text, we name the structure with one substitution per $\mathrm{O}_{24} \mathrm{H}_{4}$ the low charge structure and the structure with two substitutions per $\mathrm{O}_{24} \mathrm{H}_{4}$ the high charge structure. The main distances and angles for the two structures are given in Table 3.

It is important to point out that the structures that we consider for the calculations do not contain water molecules since we want to determine the surface energy for montmorillonite in the dry state. The intrusion of water molecules in the interlayer space makes the situation more complex and macroscopic and microscopic structures with water are still unknown.

Table 3

Selected bond lengths $(\mathrm{nm})$ and angles $\left(^{\circ}\right)$ for the two $\mathrm{Pb}$-montmorillonite structures.

\begin{tabular}{lcc}
\hline Distances & Low charge structure $(1.03 \mathrm{~nm})$ & High charge structure $(1.03 \mathrm{~nm})$ \\
\hline Al-O & 0.225 & 0.201 \\
Al-Mg & 0.298 & 0.299 \\
Al-Al & 0.298 & 0.298 \\
Si-OSi & 0.165 & 0.164 \\
Si-OAl & 0.170 & 0.164 \\
Si-OH & 0.152 & 0.161 \\
O-H & 0.077 & 0.088 \\
Si-Si & 0.295 & 0.295 \\
Mg-O & 0.190 & 0.220 \\
Angles & & \\
Si-O-Al & $133^{\circ}$ & $126.3^{\circ}$ \\
Si-O-Mg & $133^{\circ}$ & $112.6^{\circ}$ \\
Al-O-H & $116.5^{\circ}$ & $126.5^{\circ}$ \\
O-Al-OH & $101.4^{\circ}$ & $98.2^{\circ}$ \\
\hline
\end{tabular}

In addition, in the simulated structures we use (i.e. without any structural default), we also consider a perfect cleavage plane, which is usually difficult to obtain experimentally. However, this hypothesis is necessary to the development of our calculations.

\section{Results and discussion}

As presented in the Computational section, a good approximation of the surface energy is obtained from the electrostatic calculations in infinite and finite layer structures. In Fig. 2, the evolution of the difference of energy between the crystal and the finite layer is reported. A convergence of the difference is shown when 2000 atoms are considered for the finite layer. This means that the number of atoms is sufficient to determine the value to the infinite layer energy.

Different results are obtained from our calculations. First, the Total Electrostatic Balance (TEB) is determined for the different forms of montmorillonite as given in Table 4. These energy values correspond to the attractive part of the lattice energy. Values are in the same order of magnitude as those obtained for other montmorillonites (Douillard et al., 2007b), even if they are larger, which is due to the presence of divalent interlayer cations. It is noticeable that the number of substitution in the layer has an influence: when we compare the TEB values for the two structures, we do not find a simple half ratio. By comparing the same form with different interlayer distances, the TEB value decreases in absolute value, which makes sense. Indeed it is due to the decrease of the interaction between layers. This influence of the interlayer distance is not so strongly important and the partial charge for the $\mathrm{Pb}$ cation is more or less equivalent in the two forms and decreases a little when the interlayer opening increases. However, as the interlayer distance is not exactly known, the more realistic value for a plausible structure is probably an intermediate value. The surface energy corresponding to such a value taken at $1.09 \mathrm{~nm}$ is also reported in Table 5.

The comparison of partial charges has to be performed remembering that they are obtained using the Electronegativity Equalization Method and following our choices of electronegativity scale and hardness values. This is in agreement with the fact that partial charges are, quantum chemically speaking, not unique but relative. The partia charges are listed in Table 6 for the framework and in Table 7 for the interlayer cations. The comparison for the different layer charges considered in this study shows only small differences for atoms of the framework, except for aluminium and magnesium for which a large variation is observed and for the $\mathrm{OH}$ group, showing an increase of the acidity following the increase of layer charge. Furthermore $\mathrm{Al}$ (with a partial charge close to 1.3 ) and $\mathrm{Mg}$ (with a partial charge close to 1.6) are the most charged cations in the two unit cell structures respectively. The point here is that the partial charge for the aluminium decreases when the concentration of aluminium increases.

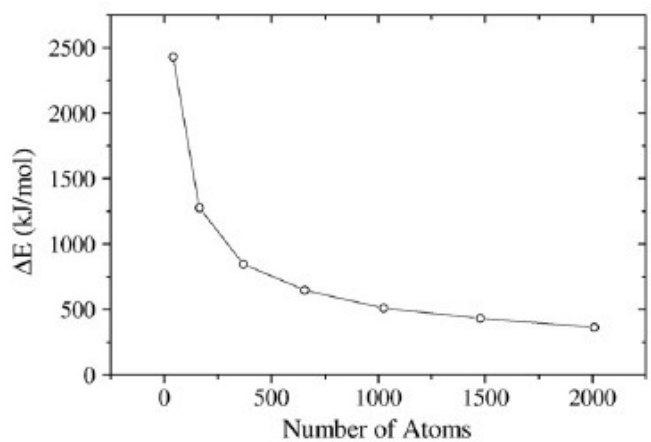

Fig. 2. Typical evolution of the energy of a layer vs the number of atoms taken inte account in the calculation. 
Table 4

Comparison of the Total Electrostatic Balance and the Electrostatic Balance for the different systems (different charges and different doo1).

\begin{tabular}{llc}
\hline Form & TEB $\left(\mathrm{kJ} \mathrm{mol} \mathrm{m}^{-1}\right)$ & EB $\left(\mathrm{kJ} \mathrm{mol}{ }^{-1}\right)$ \\
\hline High charge structure $(1.03 \mathrm{~nm})$ & $-158,578.8$ & $-10,901.4$ \\
High charge structure $(1.15 \mathrm{~nm})$ & $-150,988.4$ & -9062.1 \\
Low charge structure $(1.03 \mathrm{~nm})$ & $-160,305.0$ & $-11,419.9$ \\
Low charge structure $(1.15 \mathrm{~nm})$ & $-152,770.35$ & -9320.8 \\
\hline
\end{tabular}

This effect is well known in the zeolite family and has already been analysed by Barthomeuf $(1987,1994)$, who linked the acidity and the $\mathrm{Al}$ content in zeolites. This effect is related to the nature and quantity of electroactive atoms surrounding one aluminium and linked to the fact that two aluminium atoms cannot be directly linked, which is stated by the Loewenstein law in silicates (Loewenstein, 1954). Moreover it follows from our theoretical calculations that the substitutions are not randomly distributed in the octahedral sheet as it has been discussed from experimental NMR spectroscopy data for layered silicates (Lipsicas et al., 1984). Following these observations and more particularly the fact that the partial charges for $\mathrm{Pb}$ cations are higher in the low charge structure (corresponding to one substitution per $\mathrm{O}_{24} \mathrm{H}_{4}$ ) compared to the high charge structure (corresponding to two substitutions per $\mathrm{O}_{24} \mathrm{H}_{4}$ ), we can conclude that the low charge structure is a more realistic representation of the actual Pb-montmorillonite structure. Indeed the higher the partial charges, the stronger the interaction between interlayer cation and layer. Therefore the low charge structure is a better material for $\mathrm{Pb}$ adsorption due to the stronger electrostatic interaction.

The surface energy value can be also estimated and the results are presented in Table 5. Surface energy values depend on the layer charge of the montmorillonite and on the interlayer opening ( 1.03 or $1.15 \mathrm{~nm}$ ). This relationship with the interlayer distance is in agreement with relationships already obtained in the case of montmorillonites saturated with alkali cations (Douillard et al., 2007b). Nevertheless this last effect has not been analysed in depth, keeping in mind that the interlayer distances used here are only assumed and not experimentally measured. Due to higher partial charges calculated for the low surface charge structure, the highest surface energy value is determined in this case. However, the variation is not large. This last result implies that the impact of the repartition of the partial charges is only small for the surface energy values. Indeed, intuitively, the higher is the layer charge, the higher should be the interaction between layers. In fact, the increase of charge is blocked when the substitutions are too close. This means that the surface energy is higher in structures where the substitutions are far enough apart to lower the impact on each other. Furthermore, complementary with the previously mentioned observations, the surface energy for the low charge structure is in coherence with the values obtained in the case of Ca-montmorillonite (Haouzi et al., 2007).

As presented in the Introduction section, to elucidate the capacity of swelling clays to capture the heavy metal ions, we have to ensure that the hydration of the interlayer cations does not counterbalance the cohesion energy between clay layers. From these surface energy values, the hydration energy for both interlayer cations and layer surface can be calculated, as already presented in Salles et al. (2007) in which calculation results compare well with experimental data (Salles et al., 2008). An important hypothesis is that the heat of swelling, which is related to the enlargement of the interlayer distance in the
Table 6

Atomic charges obtained for the Pb-montmorillonite.

\begin{tabular}{lcccc}
\hline Atom & $\begin{array}{l}\text { High charge } \\
\text { structure } \\
(1.03 \mathrm{~nm})\end{array}$ & $\begin{array}{l}\text { High charge } \\
\text { structure } \\
(1.15 \mathrm{~nm})\end{array}$ & $\begin{array}{l}\text { Low charge } \\
\text { structure } \\
(1.03 \mathrm{~nm})\end{array}$ & $\begin{array}{l}\text { Low charge } \\
\text { structure } \\
(1.15 \mathrm{~nm})\end{array}$ \\
\hline $\mathrm{Si}$ & 0.865 & 0.809 & 0.87 & 0.819 \\
$\mathrm{O} 1$ & -0.499 & -0.471 & -0.531 & 0.641 \\
$\mathrm{O} 2$ & -0.485 & -0.457 & -0.531 & -0.491 \\
$\mathrm{Oh}$ & -0.55 & -0.51 & -0.531 & -0.491 \\
$\mathrm{O4}$ & -0.576 & -0.532 & -0.531 & -0.491 \\
$\mathrm{H} 1$ & 0.119 & 0.085 & 0.21 & 0.151 \\
$\mathrm{Mg}$ & 1.134 & 1.106 & 1.705 & 1.565 \\
$\mathrm{Al}$ & 1.269 & 1.35 & 0.972 & 0.911 \\
\hline
\end{tabular}

presence of water, can be neglected when we consider the total energy of the hydration process. This assumption has been validated by determining the energy between layers as a function of the interlayer distance using the same electrostatic calculations methodology (see Salles et al., 2007). Moreover it has already been shown that strong swelling does not occur in montmorillonites saturated with high charge interlayer cations (Salles et al., 2010; Ferrage et al., 2005). Then the surface energy has to be combined with the heat of immersion in order to extract the hydration energy for the whole system considered as composed of cations and layer. In the case of Pbmontmorillonite, no experimental value is available for heat of immersion. Therefore we propose to determine (i) the hydration energy of the layer from the curve linking surface energy and immersion data in the case of montmorillonites saturated with alkali cations (presented in Salles et al. (2007) and validated by conductivity measurements in Salles et al. (2008)) and then (ii) to determine the hydration energy for the $\mathrm{Pb}^{2+}$ interlayer cation from the curve linking the hydration energy of the interlayer alkali cation (i.e. in the montmorillonite structure) and the hydration energy of the alkali cation in solution (presented in Salles et al. (2007)). The correlation previously obtained (Salles et al., 2007) has shown that the ratio

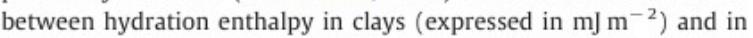
solution (expressed in $\mathrm{kJ} \mathrm{mol}^{-1}$ ) for alkali cations is around $1 / 1$; we propose to use this ratio in the case of $\mathrm{Pb}$-montmorillonite to fix the idea and to determine hydration energies. By this way the hydration energy for the $\mathrm{Pb}^{2+}$ cation in montmorillonite is estimated at about $1.5 \mathrm{~J} \mathrm{~m}^{-2}$, which corresponds to 450 and $270 \mathrm{~kJ} \mathrm{~mol}^{-1}$ if we consider the chemical formulae corresponding to 0.5 and $1 \mathrm{~Pb}$ interlayer cations respectively. These values are considerably lower than the hydration enthalpy obtained for a complete hydration in solution, which Marcus (1994) estimates to be $1570 \mathrm{~kJ} \mathrm{~mol}^{-1}$. All the simulated hydration values are reported in Table 8 . These results are in good agreement with the fact that the high charge cations (such as $\mathrm{Ni}^{2+}$ or $\mathrm{Sm}^{3+}$ ) are more strongly bonded to the water molecules compared to the $\mathrm{Na}^{+}$cations, as observed recently by QENS (Sobolev et al., 2009). The point is that the hydration energy for the interlayer cation is here predominant in the hydration process, compared to the hydration of the layer surface. This could explain the destabilisation of the crystal structure observed experimentally when adsorbing $\mathrm{Pb}^{2+}$ ions (Jozja et al., 2003). Thermal effects linked to adsorption of $\mathrm{Pb}^{2+}$ ions are probably very important and contribute to a certain breaking of the structure. In agreement with the surface energy obtained by calculations, the hydration energy for the whole systems in the case of low charge structures presents the highest value: the complete

Table 5

Surface energies obtained for the different structures.

\begin{tabular}{lllllll}
\hline Form & $\begin{array}{l}\text { High charge structure } \\
(1.03 \mathrm{~nm})\end{array}$ & $\begin{array}{l}\text { High charge structure } \\
(1.09 \mathrm{~nm})\end{array}$ & $\begin{array}{l}\text { High charge structure } \\
(1.15 \mathrm{~nm})\end{array}$ & $\begin{array}{l}\text { Low charge structure } \\
(1.03 \mathrm{~nm})\end{array}$ & $\begin{array}{l}\text { Low charge structure } \\
(1.09 \mathrm{~nm})\end{array}$ & $\begin{array}{l}\text { Low charge structure } \\
(1.15 \mathrm{~nm})\end{array}$ \\
\hline $\begin{array}{c}\text { Surface energy } \\
\left(\mathrm{mJ} \mathrm{m}^{-2}\right)\end{array}$ & 330 & 310 & 290 & 560 & 495 & 441 \\
\hline
\end{tabular}


Table 7

Atomic charges obtained for the interlayer cations as a function of the layer charge and the interlayer opening.

\begin{tabular}{ll}
\hline Form & Atomic charge obtained for the cation \\
\hline High charge structure $(1.03 \mathrm{~nm})$ & 0.489 \\
High charge structure $(1.15 \mathrm{~nm})$ & 0.538 \\
Low charge structure $(1.03 \mathrm{~nm})$ & 0.623 \\
Low charge structure $(1.15 \mathrm{~nm})$ & 0.641 \\
\hline
\end{tabular}

hydration of these solids should be the most energetic. Even if we consider that the hydration process is complete in clays, the results show clearly that the $\mathrm{Pb}$ interlayer cation is not completely hydrated (if we compare our determined value $450 \mathrm{~kJ} \mathrm{~mol}^{-1}$ to the maximum) to the expected value of $1570 \mathrm{~kJ} \mathrm{~mol}^{-1}$ (Marcus, 1994). It can be concluded that the mobility of this cation in the interlayer space must be very limited. Our results confirm the possible capacity of the swelling clays to capture heavy metal ions from the exchange of alkali cations which are more mobile (such as Li or Na interlayer cations) as already shown from conductivity measurements (Salles et al., 2008). Our results also show that the heavy metal interlayer cation will be strongly fixed to the adsorption site in the structure. The situation is enhanced in the low charge structure compared to the high charge structure, which implies that the best adsorbent for heavy metal capture is the low charge structure.

\section{Conclusion}

The study of theoretical models for Pb-montmorillonites presenting different layer charges and different interlayer openings has allowed determination of the influence of these parameters on the partial charge repartition and the surface energy values. It follows from our calculations that the precise interlayer distance has only a weak influence on the surface energy as already demonstrated for montmorillonites saturated by alkali cations (Salles et al., 2007). On the contrary, the influence of the substitution position and the layer charge are crucial. It has been found that close substitutions induce a decrease of the surface energy and the acidity (or partial charge of the cation) due to the counter-effect of each substitution on the others. This result is therefore a generalisation of the Loewenstein law and also of Barthomeuf's works (Barthomeuf, 1987; 1994) on the repartition of aluminium as a substituent for silicon in zeolites. Regarding the lack of experimental data on the structure of $\mathrm{Pb}$ montmorillonite, our work is a first step on the way to propose a structure and an efficient route to study this kind of swelling clay in the dry state. Another way to interpret our results is to consider that montmorillonites with low charge are the most efficient montmorillonites to adsorb $\mathrm{Pb}^{2+}$ cations as interlayer cations.

From this plausible structure and our surface energy results, we propose the calculation of the hydration energy for both the interlayer cation and the layer surface. These data are necessary to understand the capacity of swelling clays to capture heavy metals in their structure. At the first level obtained here, the hydration of the cation is predicted as the most exothermic process, compared to the hydration of the layer. This result is in good agreement with Quasi-Elastic Neutron Scattering data obtained recently which determined that

Table 8

Predicted hydration energies (in $\mathrm{mJ} \mathrm{m}^{-2}$ ) for interlayer cations and layer surfaces and estimation of the immersion heat for the complete system.

\begin{tabular}{llll}
\hline & Layer & Cation & Immersion \\
\hline High charge structure $(1.03 \mathrm{~nm})$ & 425 & 1500 & 1925 \\
High charge structure $(1.13 \mathrm{~nm})$ & 385 & 1500 & 1885 \\
Low charge structure $(1.03 \mathrm{~nm})$ & 630 & 1500 & 2130 \\
Low charge structure $(1.13 \mathrm{~nm})$ & 525 & 1500 & 2025 \\
\hline
\end{tabular}

cations with high charge (such as $\mathrm{Ni}^{2+}$ and $\mathrm{Sm}^{3+}$ ) are strongly bonded to the water molecules in the interlayer space (Sobolev et al., 2009). Unfortunately, to date, no experimental value is available concerning the heat of immersion, which will bring a more precise view of the hydration process.

Therefore, in order to understand the interaction between interlayer cations, layers and water molecules, future $a b$-initio calculations represent a promising way to predict more precisely the crystallographic structure and then combined with classical simulations to explain the interaction mode of the $\mathrm{Pb}$ cations in the presence of water.

\section{Acknowledgements}

The authors greatly acknowledge the financial support for this work by the French ANR within the CILSAMES project (ANR-07-JCJC-0044) and GNR PARIS 1115 (Physico-chimie des Actinides et des radioéléments aux interfaces et en solution).

\section{References}

Abollino, O., Aceto, M., Malandrino, M., Sarzanini, C., Mentasti, E., 2003. Adsorption of heavy metals on $\mathrm{Na}$-montmorillonite. Effect of $\mathrm{pH}$ and organic substances. Water Reavearch 37, 1619-1627.

Allen, LC., 1989. Electronegativity is the average one-electron energy of the valenceshell electrons in ground state free atoms. Journal of the American Chemical Society shell electrons in ground state free atoms. Journal of the American Chemical Society
$111,9003-9014$. $111,9003-9014$.

contaminated water: a review, Journal of Hazardous Materials 97, 219-243.

Barthomeuf, D., 1987. Zeolite acidity dependence on structure and chemical environment, correlations with catalysis. Materials Chemistry and Physics 17. $49-71$

Barthomeuf, D., 1994. Topological model for the compared acidity of SAPOS and SiAI zeolites. Zeolites 14, 394-401.

Bhattacharyya, K.G., Sen Gupta, S., 2008. Adsorption of a few heavy metals on natural and modified kaolinite and montmorillonite: a review. Advances in Colloid and Interface Science 140, 114-131.

Bertaut, $F_{n}$ 1952. The electrostatic energy of ionic networks. Journal de Physique et le Radium 13, 499-505.

Blanchard, G., Maunaye, M., Martin, G., 1984. Removal of heavy metals from waters by means of natural zeolites. Water Research $18,1501-1507$.

Chaturvedi, P.K., Seth, C.S., Misra, V., 2006. Sorption kinetics and leachability of heavy metal from the contaminated soil amended with immobilizing agent (humus soil and hydroxyapatite). Chemosphere 64, 1109-1114.

Douillard, J.M.. Henry, M., 2003. Calculations of surface enthalpy of solids from an ab initio electronegativity based model: case of ice. Journal of Colloid and Interface Science 263, 554-561.

Douillard, J.M., Salles, F., Henry, M., Malandrini, H., Clauss, F., 2007a. Surface energy of talc and chlorite: comparison between electronegativity calculation and immersion results. Journal of Colloid and Interface Science 305, 352-360.

Douillard, J.M., Salles, F., Devautour-Vinot, S., Manteghetti, A., Henry, M., 2007b. Study of the surface energy of montmorillonite using PACHA formalism. Journal of Colloid of the surface energy of montmorillo

Drits, V.A., Tchoubar, C., 1990. X-ray Diffraction by Disordered Lamellar Structures: Theory and Applications to Microdivided Silicates and Carbons. Springer-Verlag. Berlin, Heidelber:

Ferrage, E., Lanson, B., Sakharov, B.A., Drits, V.A., 2005. Investigation of smectite hydration properties by modelling experimental X-ray diffraction patterns: Part 1 Montmorillonite hydration properties. American Mineralogist 90, 1358-1374.

Haouzi, A., Salles, F., Henry, M., Douillard, J.M., 2007. Thermodynamic analysis of the immersion of a smectite substituted with $\mathrm{Na}$ or $\mathrm{Ca}$ : heat effect due to the cation. Journal of Colloid and Interface Science 307, 531-542.

Henry, M., 1997. In: Silvi, N., D'Arco, P. (Eds.), Modelling of Minerals and Silicated Materials. Kluwer Academic, pp. 273-334.

Huheey.J.E., Keiter, E.A., Keiter, R.L., 1993. Inorganic Chemistry: Principles of Structures and Reactivity. Harper Collins, New York

Jozja, N., Baillif, P., Touray, J.C., Pons, C.H., Muller, F., Burgevin, C., 2003. Multi-scale impacts of a $(\mathrm{Mg}, \mathrm{Ca})-\mathrm{Pb}$ exchange on the permeability increase of a bentonite. Compte-Rendu Geoscience 335, 729-736.

Lantenois, S., Prélot, B., Douillard, J.M., Szczodrowski, K., Charbonnel, M.C., 2007. Flow microcalorimetry: experimental development and application to adsorption of heavy metal cations on silica. Applied Surface Science 253, 5807-5813.

Lima, H.M., Araujo, A.C., 1994. IV meeting of the southern hemisphere on mineral technology. In: Castro, S. Concha, F. (Eds.), Mineral Processing Environment. Concepcion, Chile.

Lipsicas, M., Raythatha, R.H., Pinnavaia, T.J., Johnson, I.D., Giese, R.F., Costanzo, P.M. Robert, J.L., 1984. Silicon and aluminium site distributions in 2:1 layered silicate clays. Nature 309, 604-607.

Loewenstein, W., 1954. The distribution of aluminum in the tetrahedra of silicates and aluminosilicates. American Mineralogist 39, 92-96. 
Marcus, Y.. 1994. A simple empirical model describing the thermodynamics of hydration of ions of widely varying charges, sizes and shapes. Biophysical Chemistry $51,111-127$.

Marry, V., Turq, P., Cartailler, T., Levesque, D., 2002. Microscopic simulation of structure and dynamics of water and counterions in a monohydrated montmorillonite. The Journal of Chemical Physics 117, 3454-3463.

Matthes, W., Madsen, F.T., Kahr, G., 1999. Sorption of heavy-metal cations by Al and Zrhydroxy-intercalated and pillared bentonite. Clays and Clay Minerals 47, 617-629.

Parr, R.G., Yang. W.. 1994. Density-Functional Theory of Atoms and Molecules in International Series of Monographs on Chemistry, Vol, 16. Oxford Univ. Press, New York.

Pauling, L, 1932. The nature of the chemical bond. IV. The energy of single bonds and the relative electronegativity of atoms. Journal of the American Chemical Society 54, 3570.

Pavlovic, L., Perez, M.R., Barriga, C., Ulibarri, M.A., 2009. Adsorption of Cu2+, Cd2+, and $\mathrm{Pb} 2+$ ions by layered double hydroxides intercalated with the chelating agents diethylenetriaminepenta acetate and meso-2,3-dimercaptosuccinate Applied Clay Science $43,125-129$.

Pinnavaia, T.J., Tzou, M.-S., Landau, S.D., 1985. New chromia pillared clay catalysts. Journal of the American Chemical Society 107, 4783-4785.

Quane, D., 1970. Crystal lattice energy and Madelung constant. Journal of Chemical Education $47,396$.

Rotenberg, B., Marry, V., Vuilleumier, R., Malikova, N., Simon, C., Turq, P. 2007. Water and ions in clays: unraveling the interlayer/micropore exchange using molecular dynamics. Geochimica et Cosmochimica Acta 71, 5089-5101.

Salles, F., Henry, M., Douillard, J.M., 2006. Determination of the surface energy of kaolinite and serpentine using PACHA formalism - comparison with immersion experiments. Journal of Colloid and Interface Science 303,617-62

Salles, F., Bildstein, O., Douillard, J.M., Jullien, M., Van Damme, H., 2007. Determination of the driving force for the hydration of the swelling clays from computation of the hydration energy of the interlayer cations and the clay layer. Journal of Physical Chemistry C 111, 13170-13176.

Salles, F., Devautour-Vinot, S., Bildstein, O., Jullien, M., Maurin, G., Giuntini, J.C., Douillard, J.M., Van Damme, H., 2008. lonic mobility and hydration energies in montmorillonite clay. Journal of Physical Chemistry C 112, 14001-14009.
Salles, F., Douillard, J.M., Denoyel, R., Bildstein, O_. Jullien, M., Beurroies, I., Van Damme, H., 2009. Hydration sequence of swelling clays: evolutions of specific surface area and hydration energy. Journal of Colloid and Interface Science 333, 510-522.

Salles, F., Bildstein, O., Douillard, J.M., Jullien, M., Raynal, J., Van Damme, H., 2010. On the cation dependence of interlamellar and interparticular water and swelling in smectite clays. Langmuir $26,5028-5037$.

Sen Gupta, S., Bhattacharyya, K.G., 2008. Immobilization of Pb(II), Cd(II) and $\mathrm{Ni}($ II) ions on kaolinite and montmorillonite surfaces from aqueous medium. Journal of Environmental Management 87, 46-58.

Serrano, S., Garrido, F., Campbell, C.G., Garcia-Gonzalez, M.T., 2005. Competitive sorption of cadmium and lead in acid soils of Central Spain. Geoderma 124,91-104.

Singh, S.P., Ma, L.Q., Harris, W.Q., 2001. Heavy metal interactions with phosphatic clay: sorption and desorption behaviour. Journal of Environmental Quality 30. 1961-1968.

Sipos, P., Nemeth, T., Kis, V.K., Mohai, L., 2008. Sorption of copper, zinc and lead on soil mineral phases. Chemosphere 73, 461-469.

Skipper, N.T., Chang, F.-R.C., Sposito, G., 1995. Monte Carlo simulation of interlayer molecular structure in swelling clay minerals. 1. Methodology. Clays and Clay Minerals 43, 285-293.

Sobolev, O., Le Forestier, L., Gonzalez, M.A., Russina, M., Kemner, E.., Cuello, G.J., Charlet, L., 2009. Hydration of $\mathrm{Na}^{+}, \mathrm{Ni}^{2+}$, and $\mathrm{Sm}^{3+}$ in the interlayer of hectorite: a quasielastic neutron scattering study. Journal of Physical Chemistry C $113,13801-13812$.

Tsipurski, S.I. Drits, V.A.. 1984. The distribution of octahedral cations in the 2:1 layers of dioctahedral smectites studied by oblique texture electron diffraction. Clay dioctahedral smectites
Minerals 19, 177-193.

Vega, F.A., Covelo, E.F., Andrade, M.L., 2009. Hysteresis in the individual and competitive sorption of cadmium, copper and lead by various soil horizons. Journal of Colloid and Interface Science 331, 312-31\%

Volzone, C., 2004. Removal of metals by natural and modified clays. In: Wypych, F., Satyarayana, K.G. (Eds.), Clay Surfaces: Fundamentals and Applications. Elsevier,

Academic Press.
Yot, P.G., Méar, F.O., 2009. Influence of AIN, TiN and SiC reduction on the structural environment of lead in waste cathode-ray tubes glass: an X-ray absorption spectroscopy study. Journal of Physics: Condensed Matter 21, 285104 